\title{
Shear Characteristics of the Interface between Recycled Concrete Aggregates and Various Geosynthetics
}

\author{
Jian-Qi Wu, ${ }^{1,2}$ Lei Li, ${ }^{1,2}$ Guo-Hui Yuan $\mathbb{D}^{3}{ }^{3}$ Bin Wu, ${ }^{1,2}$ Hao Zhang, ${ }^{1,2}$ and Li-Jun Zhou $\mathbb{D}^{4}$ \\ ${ }^{1}$ College of Civil and Surveying Engineering, Jiangxi University of Science and Technology, Ganzhou 341000, Jiangxi, China \\ ${ }^{2}$ The Key Laboratory of Environmental Geotechnical and Engineering Disaster Control of Jiangxi Province, Ganzhou 341000, \\ Jiangxi, China \\ ${ }^{3}$ College of Architecture and Civil Engineering, Wenzhou University, Wenzhou 325035, Zhejiang,, China \\ ${ }^{4}$ Eye Hospital, Wenzhou Medical University, Wenzhou 325035, Zhejing, China
}

Correspondence should be addressed to Guo-Hui Yuan; yuanguohui2016@163.com and Li-Jun Zhou; 923234165@qq.com

Received 10 May 2021; Revised 25 August 2021; Accepted 27 August 2021; Published 15 September 2021

Academic Editor: Flavio Stochino

Copyright (c) 2021 Jian-Qi Wu et al. This is an open access article distributed under the Creative Commons Attribution License, which permits unrestricted use, distribution, and reproduction in any medium, provided the original work is properly cited.

To investigate the interface shear characteristics between various geosynthetics and recycled concrete aggregate (RCA), 30 largescale monotonic direct shear tests were conducted. The main work was to analyse the effect of a biaxial polypropylene geogrid, a glass fiber geogrid, a warp-knitted polyester geogrid, a woven geotextile, and geonet on the interface shear properties of RCA. The test results show that adding a biaxial polypropylene geogrid or a geonet to RCA can improve its interface shear strength. The inclusion of glass fiber geogrids, warp-knitted polyester geogrids, and woven geotextiles decrease the interface shear strength of RCA. The reinforcing RCA with geosynthetics can effectively suppress its shear dilation, and the change in internal friction angle is consistent with the change law of the material interface enhancement coefficient. Finally, the aperture size of a geogrid has a significant effect on the mechanical properties of the geogrid-RCA interface. The interface shear strength increases first and then decreases with an increase in the ratio between aperture size and median particle diameter. It is concluded that there is an optimal range of aperture ratio between a geogrid and RCA.

\section{Introduction}

In recent years, construction and demolition $(C \& D)$ waste has increased year by year, among which waste concrete is the main component, reaching $50 \%$ [1]. Recycled concrete aggregate (RCA) is a high-quality substitute for virgin aggregate as base or subgrade material in pavement construction. Recycling of construction and demolition (C\&D) waste into aggregate is environmentally beneficial by waste reduction and by preserving landfill space $[2,3]$.

Many scholars have studied the direct shear characteristics of waste concrete. Poon et al. [4,5] found that recycled concrete aggregate (RCA) in C\&D is a good substitute for natural roadbed fillers. Azam and Cameron [6] found that RCA can be used in pavements, sidewalks, and other construction applications. Alnedawi and Rahman [7] and Vieira and Pereira [8] showed through experiments that the rock properties of RCA vary only slightly, RCA can be used as a filler in reinforced structures, and it has good road performance. Those experimental studies have shown that RCA is a high-quality recycled material.

The geosynthetics are widely used in retaining walls, roadbed engineering, and dam engineering. The inclusion of geosynthetics will inevitably involve the coupling behaviour of different materials, including large displacement and strain softening behaviour [9-11]. The interaction of the stiffened interface with soil has a significant effect on the safety and stability of actual projects [12]. To analyse the shear strength of the reinforced soil interface, the direct shear test is one of the most important research methods $[13,14]$. Laboratory direct shear test studies have shown that different stress levels and different types of fillers cause great differences and complexities in the shear strengths and deformations of the interface between the reinforcement and 
the soil [15-17]. In a study of RCA applied to reinforced structures, Wang et al. [18] showed that adding a geogrid to RCA under repeated loading has a greater impact on the permanent deformation and elastic modulus. Touahaia et al. [19] studied the shear strength characteristics of RCA materials and showed that the presence of geosynthetics led to a marked increase in the shear resistance of the material and greatly restricted the deformation of a sample. Arulrajah et al. [20] used an improved large-scale direct shear instrument to determine the shear test results of C\&D aggregates and reinforced materials. They detected the interface shear resistance of reinforced concrete by using the improved direct shear test device. The shear resistance was higher than that found using the conventional test method, and they found that, among the reinforced C\&D materials, RCA had the highest interfacial peak shear strength and interfacial residual shear strength.

Existing experimental research has focussed mainly on the shear properties of the material itself, which shows good road performance. In the analyses of the reinforced recycle concrete aggregate interface, most of them focus on analysing the interface shear characteristics affected by other factors with the same geosynthetic. However, few direct shear tests have been performed on the interfaces between RCA and various geosynthetics. To better understand the shear mechanism of reinforced recycle concrete aggregate interface, a series of direct shear tests were conducted in this study on the interface between RCA with various geosynthetics types. The aim in this paper is to analyse the influence of various geosynthetic types, geogrid aperture sizes, and normal stresses on the shear strength of the reinforced RCA interface through large-scale direct shear apparatus.

\section{Experimental Investigation}

2.1. Test Apparatus. The apparatus used in this research was a Shear Trac III indoor large-scale direct shear apparatus (Geocomp, USA). The size and structure of the upper and lower boxes of the apparatus are shown in Figure 1. The length of the lower shear box in the shear direction is longer than that of the upper shear box. This different direct shear box size is used to ensure that the shear area remains unchanged while avoiding influencing the experiment by reducing the shear area. The shear displacement range was 0 to $100 \mathrm{~mm}$, and the adjustable maximum shear rate was $15 \mathrm{~mm} / \mathrm{min}$. The test data were automatically read and recorded by the data software.

\subsection{Test Materials}

2.2.1. Recycled Concrete Aggregate and Gravel. The RCAs in this test were taken from a demolition site near Chashan Town in Wenzhou, Zhejiang Province, China. Samples were collected manually at the site, and the RCA was taken to the test site for air drying before preliminary screening. It was then broken by a crusher to reduce its particle size and increase material uniformity. In accordance with the Chinese standard JTG F102006, "Technical Specification for Highway Subgrade Construction" [21], the RCA was screened, and particles ranging from 4.75 to $26.5 \mathrm{~mm}$ in size were taken as the test samples. In accordance with the requirements of the Chinese standard GB/ T 50123-1999 “Geotechnical Test Method Standard" [22] for intermediate and off-line grading, RCAs of various particle size ranges were formulated into material S1 with good gradation according to a certain ratio. Gravel S2 was made by Wenzhou University. The dry density of RCA was between 1.695 and $1.89 \mathrm{~g} / \mathrm{cm}^{3}$, and its natural water content was between $2.2 \%$ and $3.7 \%$. The California bearing ratio (CBR) of RCA is about $51.2 \%$, which meets the requirements of the filling strength of the highway subgrade. As a comparison group, building materials used in the structural laboratory were used, as shown in Figure 2. The gradation curves and physical parameters of the two test materials are shown in Figure 3.

2.2.2. Geosynthetics. The geosynthetics used in the test are shown in Figure 4. There were five kinds of reinforced materials: polypropylene geogrid (PG), fiberglass geogrid (FG), warp-knitted polyester geogrid (WK), woven geotextile (WG), and geonet (GT). PGs of four different aperture sizes were used, including 25/25, 30/30,35/35, and 40/ 40; the technical characteristics of the geosynthetics types are shown in Table 1.

2.2.3. Test Programme. This test was conducted under normal stress conditions of $60 \mathrm{kPa}, 90 \mathrm{kPa}$, and $120 \mathrm{kPa}$; the monotonic direct shear test (MDS) of the interface was conducted between RCA and five different geosynthetic reinforcement types; RCA was conducted with four different grid mesh sizes for the PG materials. The test programme is shown in Table 2. In accordance with China's standard JTG E50-2006, "Test Regulations for Geosynthetics of Highway Engineering" and previous research results [23], the shear rate of each group of tests was set to $1 \mathrm{~mm} / \mathrm{min}$. Compactness control of the RCA test material was a key point. According to the classification standards for relative density, Dr, the sand samples are divided into three kinds of compaction states: loose sand ( $\mathrm{Dr}<1 / 3)$, medium density sand $(1 / 3<\mathrm{Dr} \leq 2 / 3)$, and dense sand $(\mathrm{Dr} \geq 2 / 3)$. The RCA sample with $90 \%$ density is selected in this research. Because the volume of the direct shear box remained constant, a sample with a certain total mass was divided into five $2-\mathrm{cm}$ thick layers in accordance with the layered filling method. The quality of the RCA and gravel loaded into the shear box was controlled, and they were tamped with a normal hammer to control the packing density to the calibrated height and to ensure that the density of each test sample was consistent. The geosynthetics used in the tests were fixed on the lower shear box by packing with its steel plate and bolts.

\section{Results and Discussion}

3.1. Stress-Strain Test Results of Gravel and RCA. Before the stress-strain relation curves between RCA and various geosynthetic types were derived, a shear strength analysis of the interface between gravel and RCA was used as a reference. Figure 5 shows the shear test results of gravel and RCA under various normal stress conditions. From Figure 5(a), it can be 

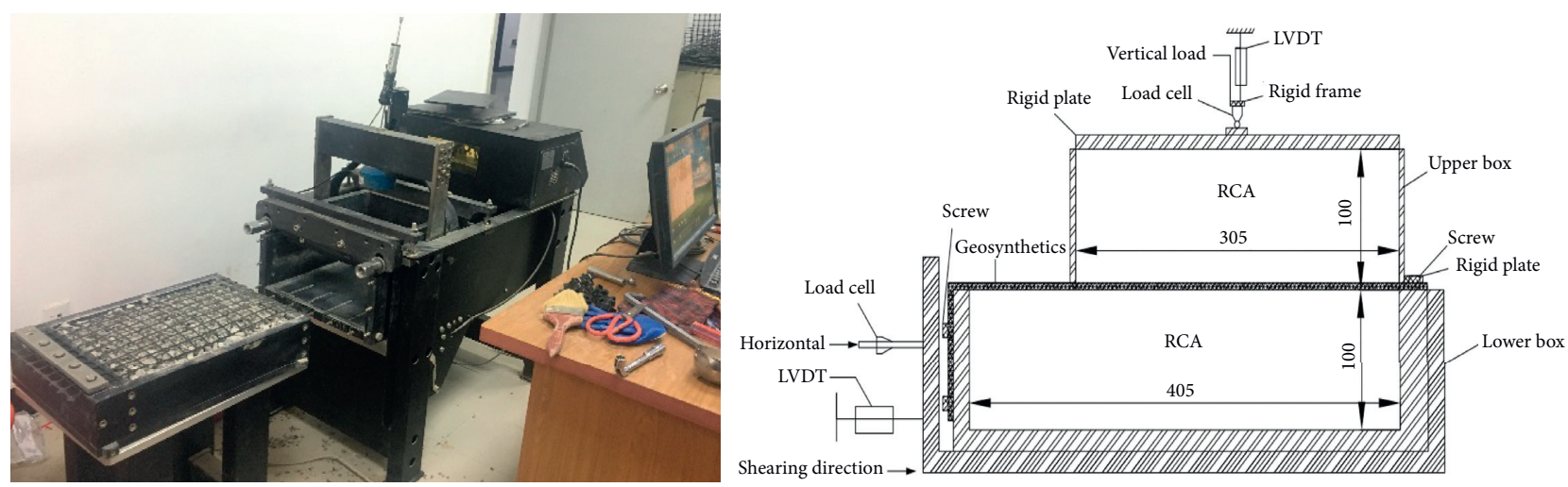

FIGURE 1: Large-scale direct shear apparatus (unit: $\mathrm{mm}$ ).

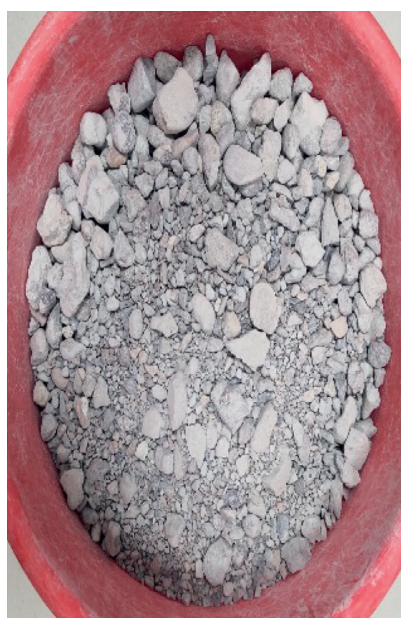

(a)

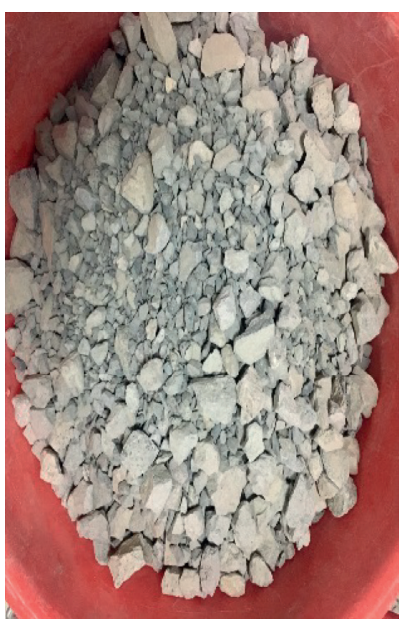

(b)

FIgURE 2: (a) Test RCA and (b) crushed gravel.

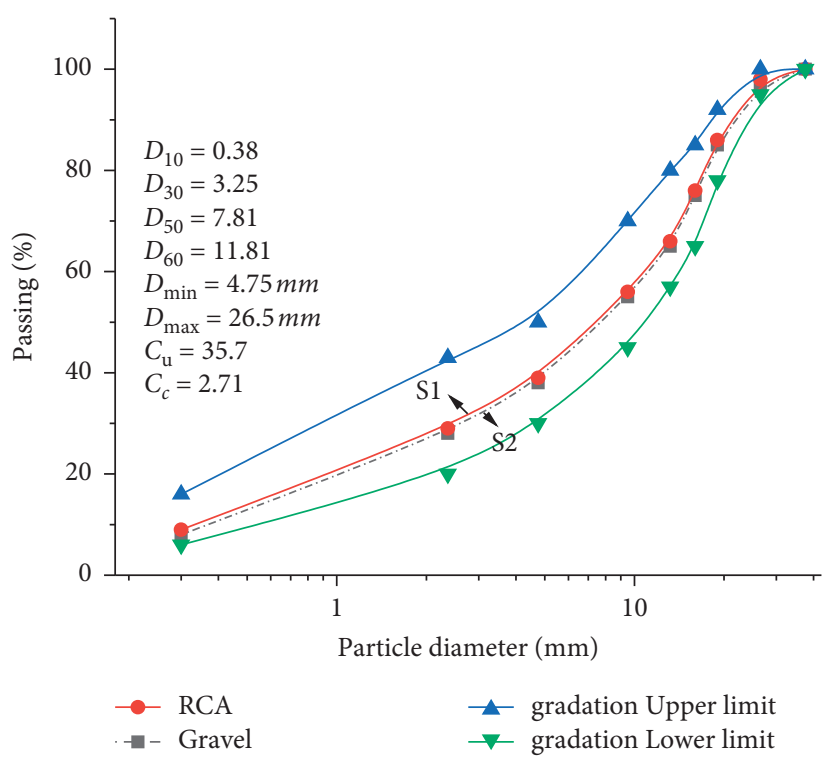

Figure 3: Distribution curve of RCA and gravel. 


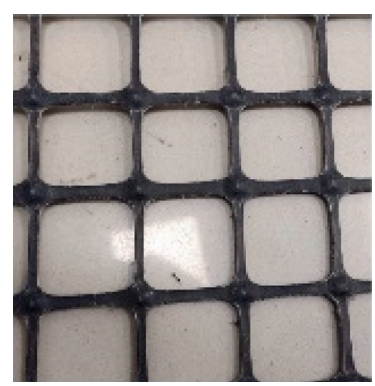

(a)

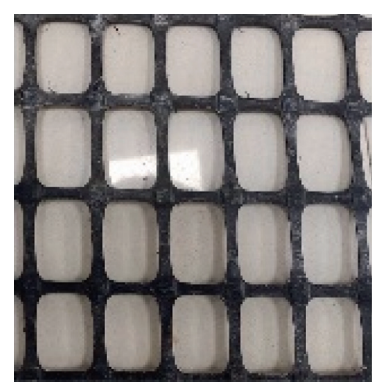

(e)

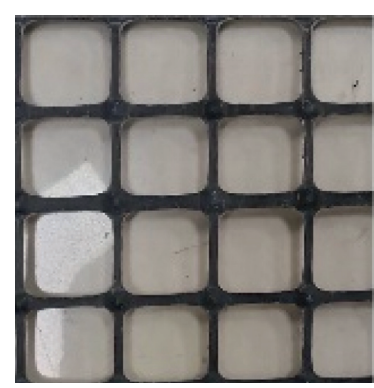

(b)

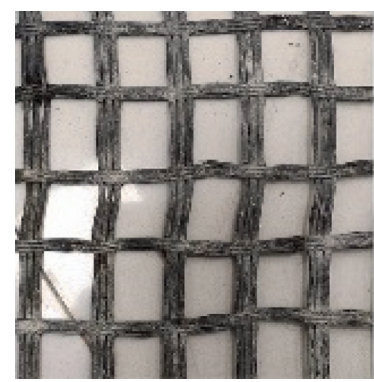

(f)

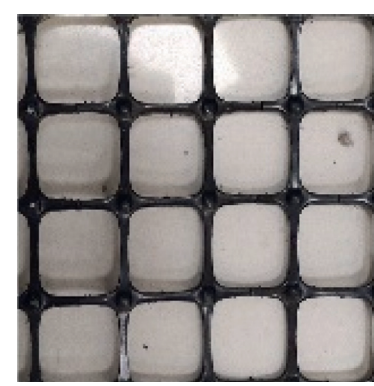

(c)

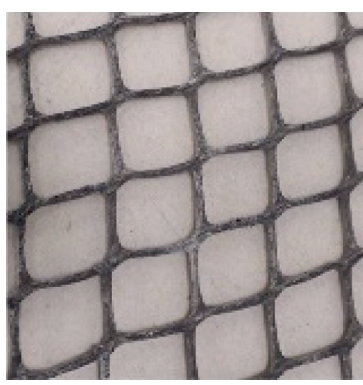

(g)

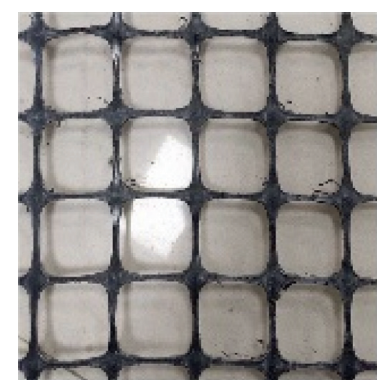

(d)

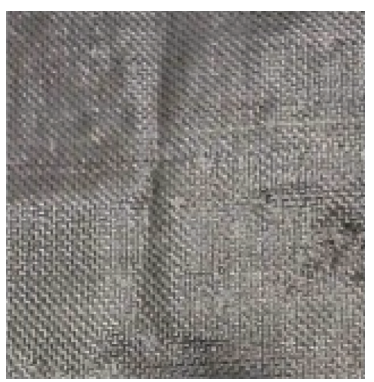

(h)

Figure 4: Reinforced materials for testing. (a) $25 \mathrm{~mm}$ polypropylene geogrid (PG). (b) $30 \mathrm{~mm}$ PG. (c) 35 mm PG. (d) 40 mm PG. (e) Warpknitted polyester geogrid. (f) Fiberglass geogrid. (g) Geonet. (h) Woven geotextile.

TABLE 1: Technical characteristics of reinforced material.

\begin{tabular}{|c|c|c|c|c|c|c|c|}
\hline \multirow[t]{2}{*}{ Geosynthetic type } & \multirow[t]{2}{*}{ Mass per unit area $\left(\mathrm{g} \cdot \mathrm{m}^{-2}\right)$} & \multirow[t]{2}{*}{ Aperture size $(\mathrm{mm})$} & \multirow[t]{2}{*}{$\mathrm{LD}^{1}$ and $\mathrm{TD}^{2}$ ribs width $(\mathrm{mm})$} & \multicolumn{2}{|c|}{$\begin{array}{c}\text { Tensile } \\
\text { strength } \\
\text { at } 2 \% \\
\text { strain } \\
\left(\mathrm{kNm}^{-1}\right)\end{array}$} & \multicolumn{2}{|c|}{$\begin{array}{c}\text { Ultimate } \\
\text { tensile } \\
\text { strength } \\
\left(\mathrm{kNm}^{-1}\right)\end{array}$} \\
\hline & & & & $\mathrm{TD}$ & $\mathrm{LD}$ & TD & LD \\
\hline Polypropylene geogrid & 330 & $\begin{array}{l}25 \times 25 \\
30 \times 30 \\
35 \times 35 \\
40 \times 40\end{array}$ & 5,5 & 9.5 & 9.7 & 24.5 & 23.2 \\
\hline Fiberglass geogrid & 220 & 2525 & 8,8 & 2.7 & 2.8 & 24 & 23 \\
\hline Warp-knitted polyester geogrid & 300 & $25 \times 25$ & 5,5 & 9.6 & 11.5 & 22.3 & 21.5 \\
\hline Woven geotextile & 200 & - & 1,5 & 19.8 & 19.8 & 3.7 & 3.7 \\
\hline Geonet & 660 & $25 \times 25$ & 4,4 & 16.5 & 16.5 & 5.8 & 5.8 \\
\hline
\end{tabular}

LD, longitudinal direction; TD, transverse direction.

TABLE 2: Monotonic direct shear test scheme.

\begin{tabular}{|c|c|c|c|c|}
\hline Test type & Test specimen & Geosynthetic type & Normal stress $(\mathrm{kPa})$ & Shearing rate $\left(\mathrm{mm}-\mathrm{min}^{-1}\right)$ \\
\hline Unreinforced & RCA and gravel & - & $60,90,120$ & 1 \\
\hline Reinforced & RCA & PG, FG, WK, WG, GT & $60,90,120$ & \\
\hline
\end{tabular}

seen that the stress-strain curves of gravel and RCA appear similar under various normal stresses, and the peak shear strength of gravel and RCA increased markedly as the normal stress increased. When the normal stresses were $60 \mathrm{kPa}, 90 \mathrm{kPa}$, and $120 \mathrm{kPa}$, the peak shear strengths of the interface corresponding to RCA were $153.4 \mathrm{kPa}, 227.5 \mathrm{kPa}$, and $315.1 \mathrm{kPa}$, respectively, and the peak shear strengths of the interface corresponding to the gravel were $179.6 \mathrm{kPa}, 267.6 \mathrm{kPa}$, and
$368.6 \mathrm{kPa}$, respectively. The shear stresses of gravel and RCA both reached the peak first, and then, the shear stresses decreased with the increase in shear displacement and gradually became gentle, showing obvious shear softening, and the softening characteristic of the gravel was more obvious than that of the RCA. When the gravel and RCA reached the residual shear strength, the shear displacement used by the RCA was greater than that of the gravel. 


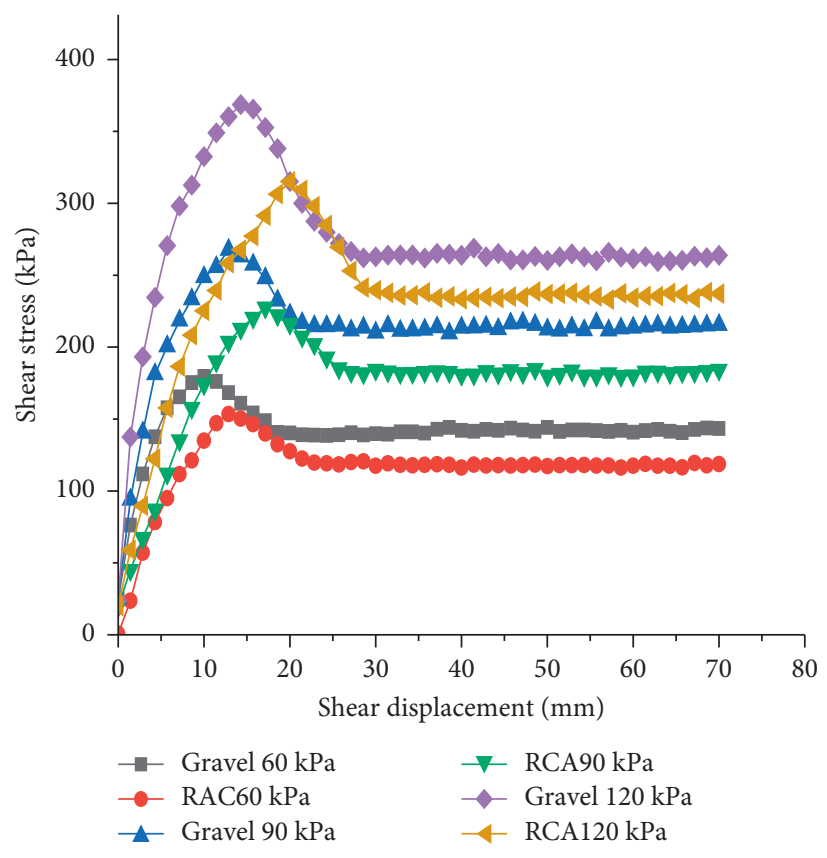

(a)

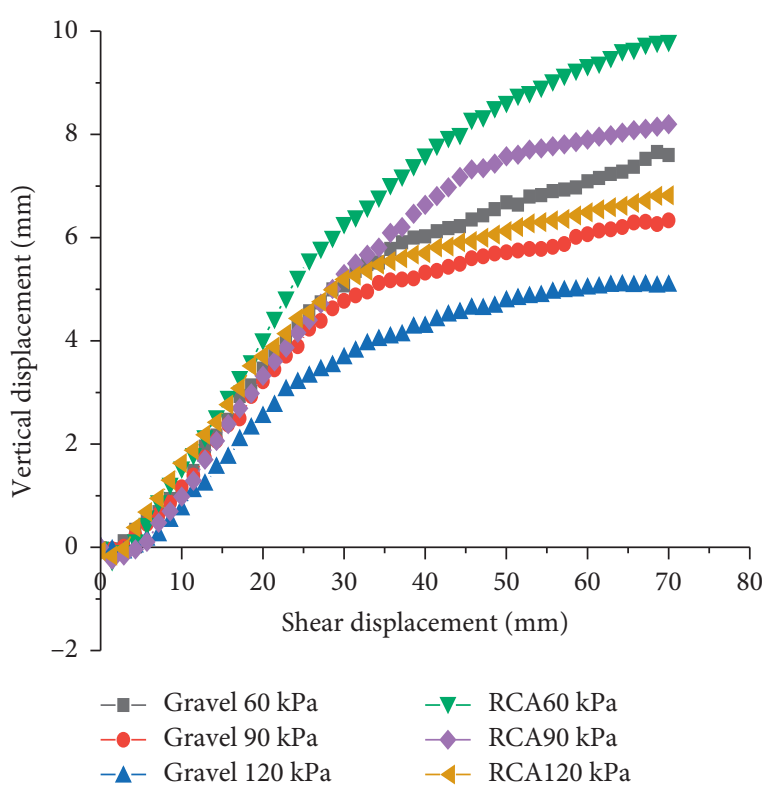

(b)

FIGURE 5: Shear stresses and vertical displacement results of RCA and gravel for various shear displacements and normal stresses.(a) Shear displacement-shear stress relationship curve between RCA and gravel; (b) RCA and gravel shear displacement-vertical displacement relation curve.

Because the shear area remained unchanged in the test, the vertical displacement development law of the contact surface could represent the shear body deformation development law of the shear surface during the shearing process. In this test, the shear dilatation was positive and the shear shrinkage was negative [24]. As shown in Figure 5(b), in the initial stage of shearing, both the gravel and the shear surface of RCA had a short-term shear shrinkage deformation, and then, the gravel and RCA shear surfaces expanded relatively rapidly. The growth rate of the interface dilatancy decreased gradually with the increase in shear displacement. Figure 5(a) shows that the shear deformation of the gravel and RCA decreased markedly with the increase in the normal stress. This phenomenon can be explained by the free-rolling of the gravel and RCA due to the continuous increase in the normal stress. Climbing behaviour was restricted. Large vertical pressure hindered the free movement of the specimen, resulting in a smaller shear deformation. Under the same normal stress conditions, the shear deformation of the RCA was greater than that of the gravel.

Figure 6 shows the envelope curves of the peak shear strength of the interface between gravel and RCA under various normal stresses. The figure shows that the value of the correlation coefficient $R^{2}$ is close to 1 , and the interface shear strength shows a close linear correlation to the normal stress. The Mohr-Coulomb model, $\tau=c+\sigma \tan \phi$, can be used to describe the interface shear strength, so the RCA was obtained in the experiment. The internal friction angle of the RCA was $68.9^{\circ}$, and the internal friction angle of the gravel was $71.5^{\circ}$.
3.2. Influence of Various Geosynthetics Types on the Shear Strength of the RCA Interface. Figure 7(a) shows the shear test results of RCA and various geosynthetic types under a normal stress of $90 \mathrm{kPa}$. Figure 7 shows that the interfacial shear test results of PG-RCA, FG-RCA, WK-RCA, and GTRCA all show obvious shear softening. The inflection point and the interface shear test result of WG-RCA show shear hardening; the peak shear strength of PG-RCA was the highest, reaching $267.2 \mathrm{kPa}$, followed by that of GT-RCA at $237.7 \mathrm{kPa}$. Relative to RCA by itself, FG-RCA, WK-RCA, and WG-RCA had lower interface peak shear strengths; the strengths were $215.9 \mathrm{kPa}, 205.9 \mathrm{kPa}$, and $222.1 \mathrm{kPa}$, respectively. Figure 7(b) shows that the interface shear results of the reinforced RCA have obvious dilatancy, but a small amount of shear shrinkage appears in the initial stage. This is because the particles were rearranged, and the interstices of the particles were filled with smaller particles, causing the RCA to temporarily shrink. When dilatancy occurred and the dilatancy rate became smaller, the interface shear strength reached its peak.

When the influences of various geosynthetic types on the shear strength of RCA were analysed, the concept of interface enhancement coefficient $\alpha$ [25] was introduced. Quantitative analysis and the evaluation of an RCA reinforced interface were based on the $\alpha$ value. The ratio of the shear strength of a reinforced interface to the shear strength of an unreinforced interface was defined as $\alpha$ :

$$
\alpha=\frac{\tau_{\text {Reinforced }}}{\tau_{\text {Unreinforced }}}
$$




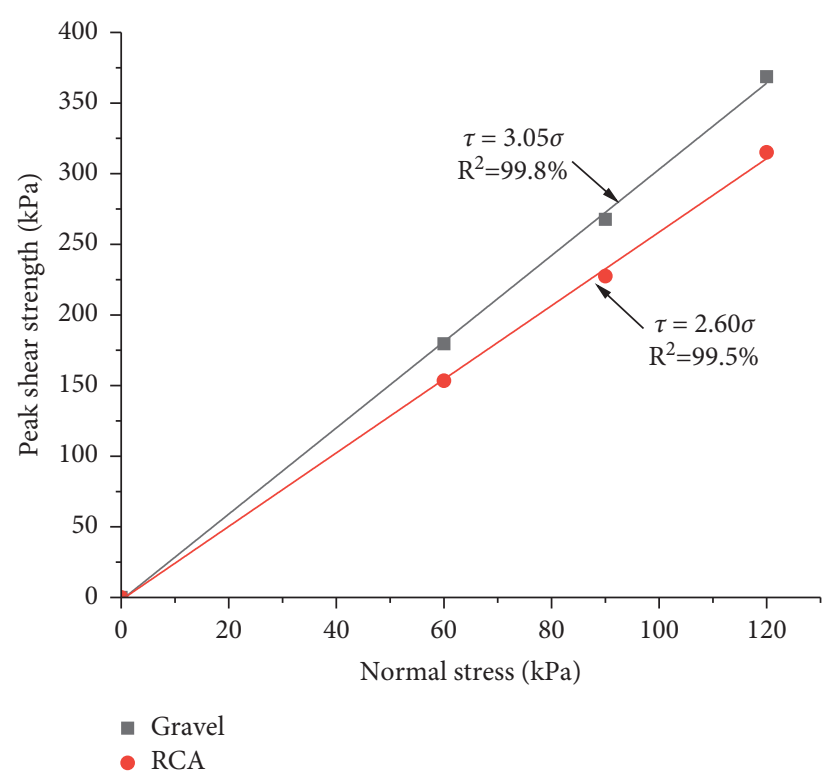

FIGURE 6: Relation curves of peak shear strength and normal stress for RCA and gravel.

where $\tau_{\text {Reinforced }}$ is the interface shear strength of RCA and various geosynthetics and $\tau_{\text {Unreinforced }}$ is the shear strength of RCA.

Adding stiffened materials can markedly reduce the degree of interfacial shear dilatancy [26], which results from the interactions between geosynthetics and RCA. To evaluate the reinforced RCA, the interfacial shear expansion coefficient $(\eta)$ [27] was introduced. The value of $\eta$ was defined as

$$
\eta=\frac{\omega_{s d}}{\omega_{s c}},
$$

where $\omega_{s d}$ is the relative expansion displacement during the shearing process and $\omega_{s c}$ is the relative compression displacement during the shearing process. Suppress the expansion coefficient $\eta$ value as shown in Figure 8. The figure shows that the $\eta$ values of the PG-RCA, GT-RCA, WK-RCA, WG-RCA, and FG-RCA were 30.27, 27.2, 40.38, 46.84, and 42.93, respectively.

In Table 3, the $\alpha$ values of various reinforced RCA interfaces are obtained by comparison. The fluctuation range of the $\alpha$ values of the interfaces is from 0.91 to 1.17. PG-RCA has the highest $\alpha$ value, followed by GT-RCA. WK-RCA, FG-RCA, and WG-RCA have an $\alpha$ value of less than 1 (that is, unreinforced RCA). An $\alpha$ value greater than 1 represents a beneficial reinforcement effect of the geosynthetics in the $\mathrm{RCA}$ reinforced interface. The shear strength of the interface came mainly from the "passive resistance" effect of the geogrid cross ribs and the interfacial particles (i.e., a particlemesh interaction lock). Because of the interlocking mechanism, adding geosynthetics can enhance the shear strength of the RCA interface. The main reason is that relative to the interactions between RCA particles alone, interface particles can better limit the free sliding or rotation of RCA and hence provide higher shear strength. The $\alpha$ values of WK-RCA and FG-RCA were both less than 1 because the RCA particles were larger than the WK and FG apertures, which mitigated the interlocking effect between the particles and the apertures. Furthermore, some portions of the WK and FG incurred damage, leading to failure of the reinforcement. The $\alpha$ value of the WG-RCA interface is less than 1 because the addition of WG increases the area of the shear weakening surface and hinders the interlocking between RCA particles. To improve the frictional resistance of WG, the RCA particles need to be rearranged when shear occurs, and the interaction between the arranged RCA particles and WG is less than the interlocking effect between RCA particles. The PG-RCA and GT-RCA had an $\alpha$ value greater than 1 because of the better ultimate elongation of the PG and GT reinforcing materials. Geogrid cross ribs can provide higher passive resistance and better interlocking. The possible reason for the softening phenomenon after the peak is that the RCA particles continued to wear and break during the shearing process, causing the shear surface to slip. As the shear displacement increased, the shear strength reached the residual shear strength and tended to stabilize.

Figure 9 shows the envelope relation curves of the peak shear strengths of the interface under monotonic direct shear conditions for RCA and five reinforced RCAs. The influence of various geosynthetic types on the values of cohesive force $c$ and internal friction angle $\varphi$ was analysed. The RCA internal friction angle was $\varphi=68.9^{\circ}$. For the PGRCA interface, $c=23.7 \mathrm{kPa}$ and $\varphi=69.2^{\circ}$; for the WK-RCA interface, $c=22.4 \mathrm{kPa}$ and $\varphi=64.2^{\circ}$; for the GT-RCA interface, $c=5.2 \mathrm{kPa}$ and $\varphi=68.8^{\circ}$; for the WG-RCA interface, $c=8.6 \mathrm{kPa}$ and $\varphi=67.9^{\circ}$; for the FG-RCA interface, $c=14.9 \mathrm{kPa}$ and $\varphi=65.4^{\circ}$.

From the above data, it can be seen that the value of the internal friction angle increased and decreased, and the range of the $\varphi$ value fluctuations was from $64.2^{\circ}$ to $69.2^{\circ}$. The values of the cohesive force for the interfaces from large to small were PG-RCA, WK-RCA, FG-RCA, WG-RCA, and GT-RCA. 


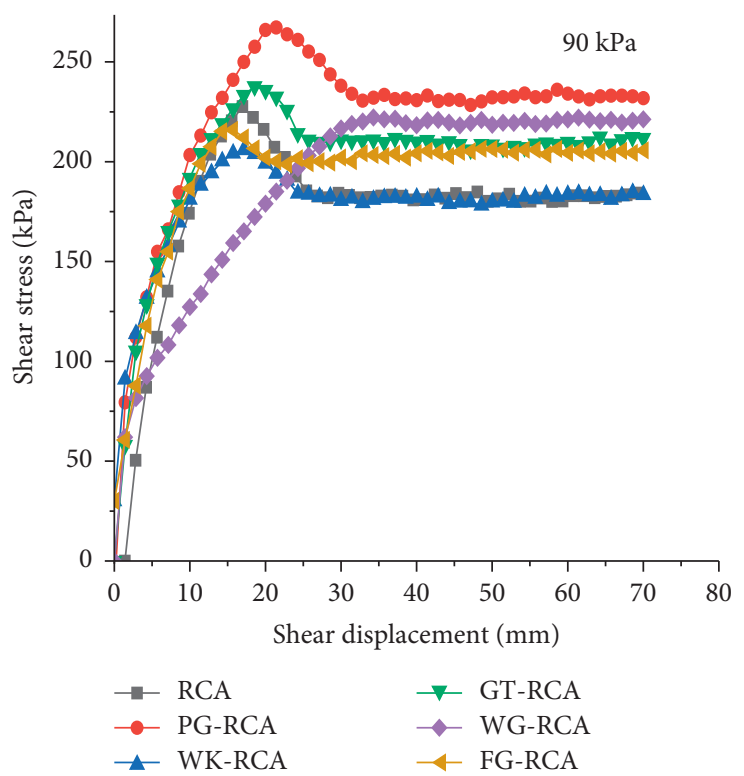

(a)

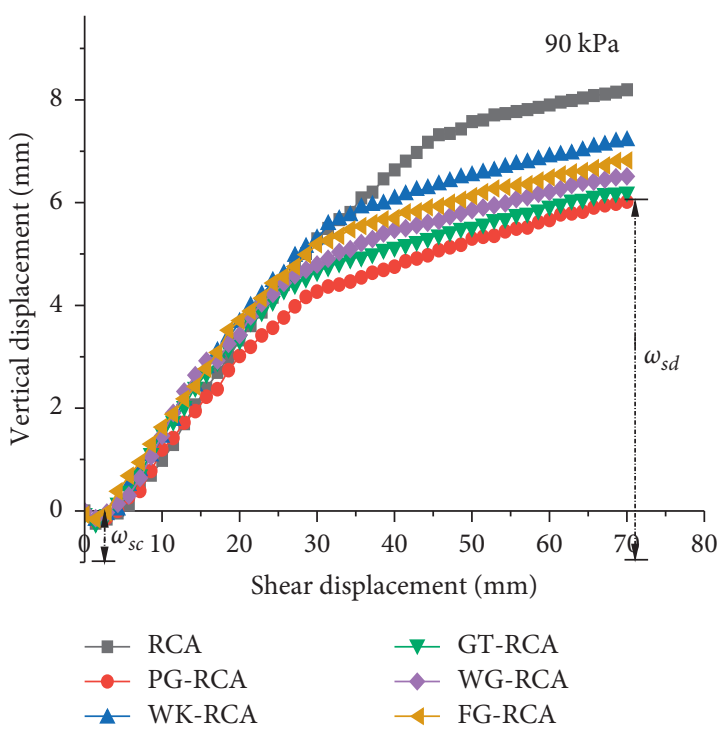

(b)

FIGURE 7: Shear stresses and vertical displacement results of various geosynthetics and RCA for various shear displacements. (a) Shear displacement-shear stress relation curve between RCA and different geosynthetics. (b) Shear displacement-vertical displacement curves of different geosynthetics and RCA.

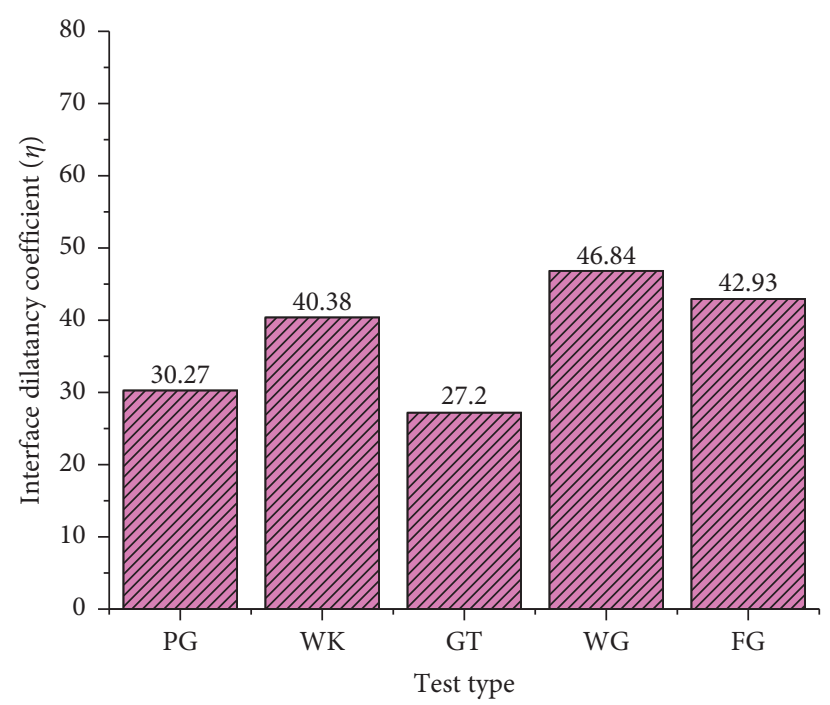

Figure 8: Results of tests for the interface dilatancy coefficient $(\eta)$ of various geosynthetics.

3.3. Effect of Aperture Size on the Shear Characteristics of the $P G-R C A$ Interface. Figure 10(a) shows the shear results of the PG-RCA interface with various geogrid aperture sizes (FD) under $90 \mathrm{kPa}$ normal stress compared with the RCA test group. The interface shear strengths of PG-RCA for various FD values all showed obvious shear softening. Relative to the RCA test group, the shear strengths of PGRCA were markedly enhanced. As shown in Figure 10(a), when the shear stresses were maximum, the FD was 35. Furthermore, PG exhibited the greatest shear strength. Figure 10(b) shows that the PG-RCA interface for the various FDs had obvious dilatancy. Adding the PG obviously inhibited the dilatancy degree of the RCA. The $\eta$ values of
PG-RCA with size diameters of $25 \mathrm{~mm}, 30 \mathrm{~mm}, 35 \mathrm{~mm}$, and $40 \mathrm{~mm}$ were $30.27,28.83,27.29$, and 33.37 respectively.

To analyse the degree of influence of the $F_{D}$ value on the shear strength of the PG-RCA interface, a correlation curve was drawn of the interface enhancement coefficient $\alpha$ and the porosity ratio $F_{D} / D_{50}\left(D_{50}\right.$ is the median diameter in the RCA particle gradation), and the change law between the $\alpha$ value and $F_{D} / D_{50}$ was analysed. Figure 11 shows that the ratio of the $\alpha$ value to $F_{D} / D_{50}$ first increased and then decreased. When the $F_{D} / D_{50}$ ratio equalled to 4.48 , the maximum value of $\alpha$ reached 1.33. Then, as the ratio of $F_{D} / D_{50}$ gradually increased, the value of $\alpha$ gradually decreased. 
TABLE 3: Interface efficiency factor $\alpha$ values of RCA and various geosynthetics.

\begin{tabular}{lccc}
\hline Geosynthetic & Aperture size $(\mathrm{mm})$ & Peak shear strength of interface $(\mathrm{kPa})$ & Interface enhancement factor $(\alpha)$ \\
\hline PG & $25 \times 25$ & 267.2 & 1.17 \\
WK & $25 \times 25$ & 205.9 & 0.91 \\
FG & $25 \times 25$ & 215.9 & 0.95 \\
WG & - & 222.1 & 0.98 \\
GT & $25 \times 25$ & 237.7 & 1.04 \\
\hline
\end{tabular}

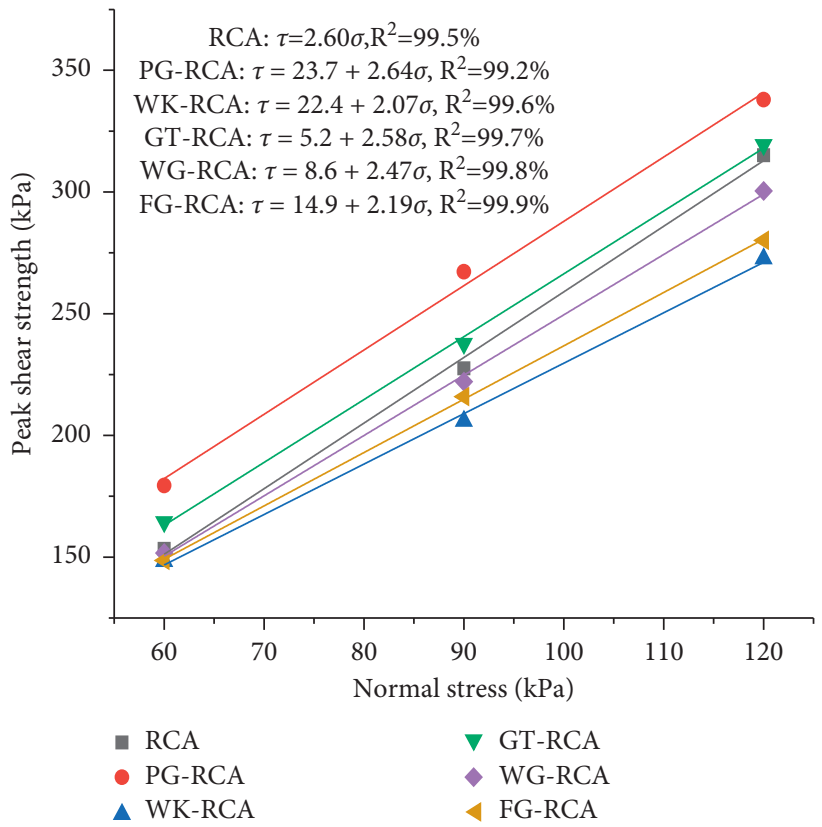

FIGURE 9: Interface peak shear strengths of various geosynthetics and RCA for various normal stresses.

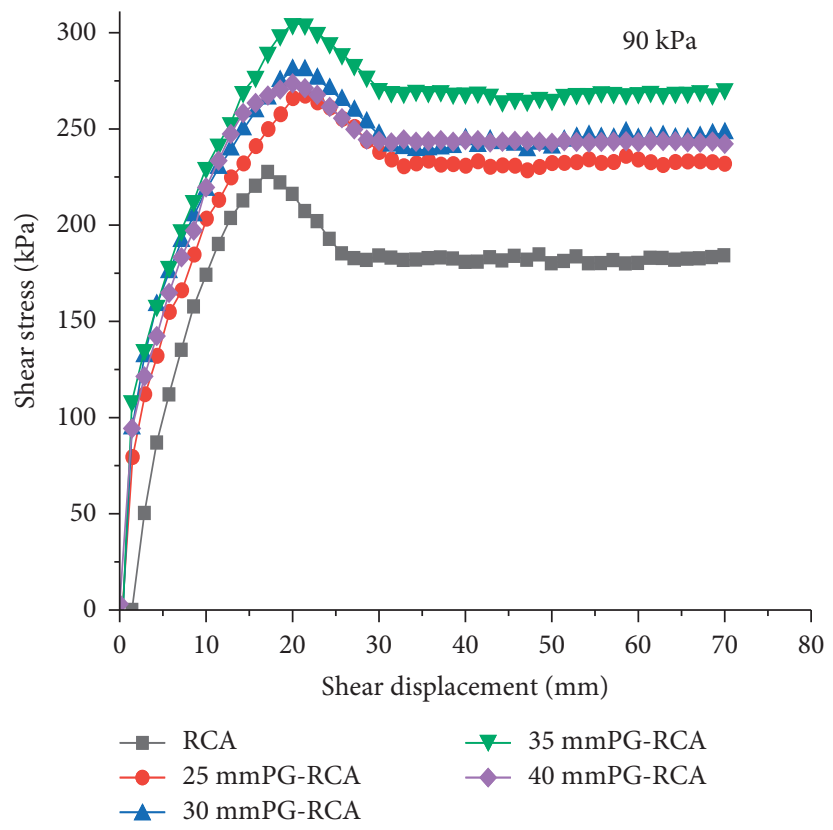

(a)

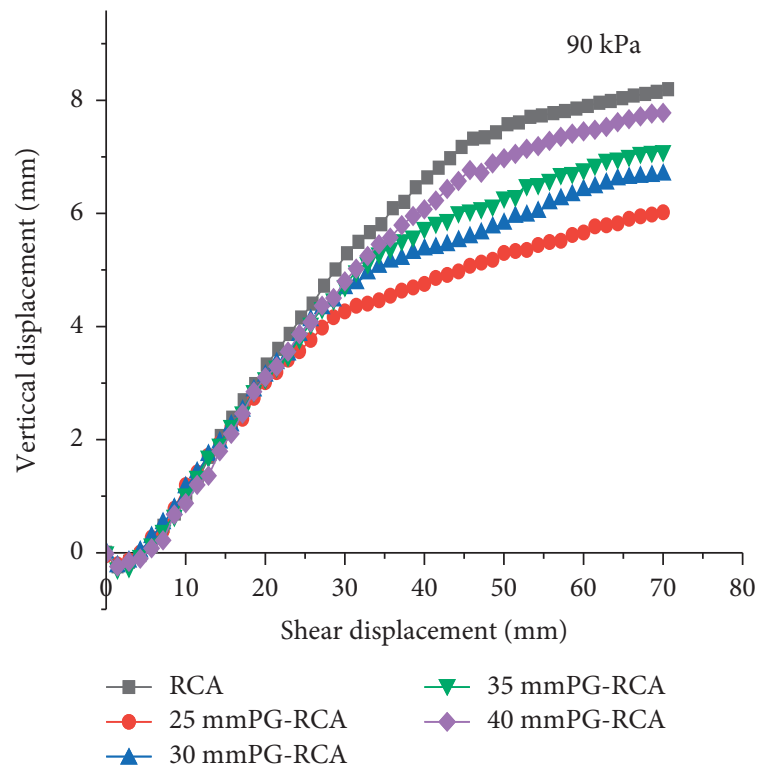

(b)

Figure 10: Shear stresses and vertical displacements of RCA and PG-RCA for various aperture sizes and shear displacements. (a) Shear displacement-shear stress curve of PG and RCA with different aperture sizes. (b) Vertical displacement-shear displacement curve of PG and RCA with different aperture sizes. 


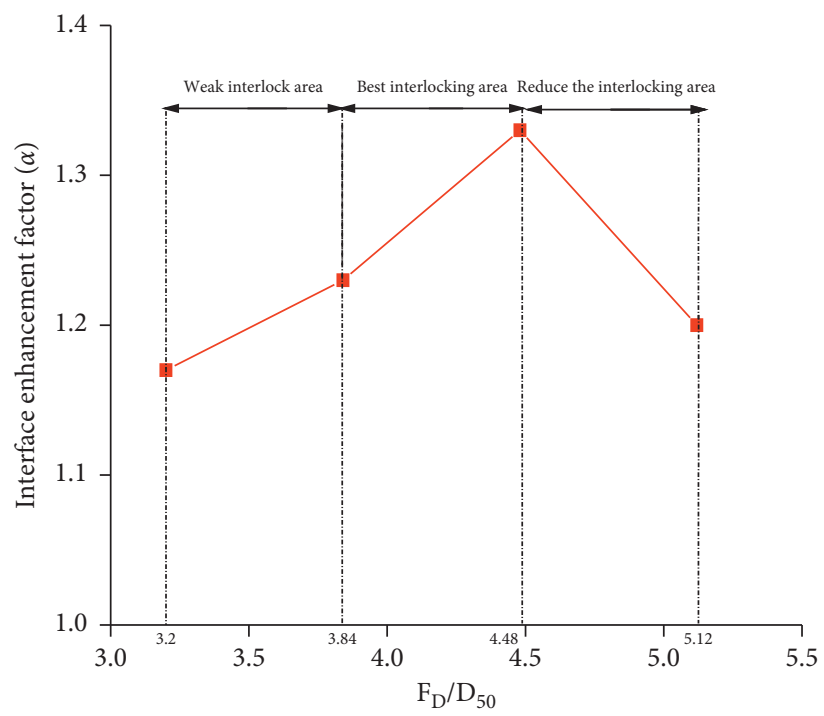

FIgURE 11: Relation curve of interface enhancement factor and $F_{D} / D_{50}$.

Furthermore, it can be seen that the $\alpha$ value corresponding to the test ratio $F_{D} / D_{50}$ was greater than 1 . This shows that all tested PG materials with a ratio of $F_{D} / D_{50}$ enhanced the shear strength of the interface. In other words, when $\alpha$ equalled to 1 , the corresponding $F_{D} / D_{50}$ ratio was the minimum aperture requirement for the geogrids. According to the changes in the ratio $F_{D} / D_{50}$, it was divided into three main areas: a weak interlock area ranging from 3.2 to 3.84 , a best interlock area ranging from 3.84 to 4.48 , and a reduced interlock area ranging from 4.48 to 5.12 .

\section{Conclusions}

In this study, a large-scale direct shear apparatus was used to comprehensively analyse the mechanical characteristics of RCA and various geosynthetic types, geogrid aperture sizes, and interface interactions under various normal stresses. A total of 30 sets of monotonic direct shear tests were completed. The main conclusions are as follows:

(1) In monotonic direct shear, both the gravel and the RCA had high interface shear strength, and the interface shear strength increased markedly with an increase in normal pressure. Both the RCA and the gravel interface showed obvious shear softening. The shear softening of the RCA was less than that of the gravel, and the internal friction angle of the RCA was slightly lower than that of gravel.

(2) The influence of different geosynthetic types on the shear strengths of the RCA reinforced interfaces was quite different. The peak shear strengths of the interfaces, in descending order, were PG-RCA, GTRCA, WG-RCA, FG-RCA, and WK-RCA. The change law of the internal friction angle was consistent with the change law of the interface reinforcement coefficient. Adding geosynthetics obviously suppressed the shear deformation of RCA. This study provides an important basis for selecting suitable geosynthetic types in actual projects and is of great significance to sensitive components that have a great effect on subgrade settlement.

(3) The $F_{D}$ value of the PG has a marked effect on the shear strength of the PG-RCA interface. The shear strength of that interface first increased and then decreased with an increase in the grain-to-pore ratio. The ratio $F_{D} / D_{50}$ was divided into three key areas: a weak interlock area, a best interlock area, and a reduced interlock area. The best interlock area range was an $F_{D} / D_{50}$ ratio of from 3.84 to 4.48 . This provides an important basis for selecting appropriate geogrid aperture sizes in actual engineering.

\section{Data Availability}

The data used to support the findings of this study are available from the corresponding author upon request.

\section{Conflicts of Interest}

The authors declare that they have no conflicts of interest regarding the publication of this paper.

\section{Acknowledgments}

This work was supported by the National Natural Science Foundation of China (Grant nos. 51768024 and 51768025) and National Science Foundation for Young Scientists of China (Grant no. 52108338).

\section{References}

[1] A. Arulrajah, J. Piratheepan, and M. Ali, "Geotechnical properties of recycled concrete aggregate in pavement subbase applications," Geotechnical Testing Journal, vol. 35, no. 5, pp. 743-751, 2012.

[2] J. Zhang, "Performance evaluation of cement stabilized recycled mixture with recycled concrete aggregate and 
crushed brick," Construction and Building Materials, vol. 296, Article ID 123596, 2021.

[3] B. Lei, W. Li, Z. Tang, and Z. Li, "Effects of environmental actions, recycled aggregate quality and modification treatments on durability performance of recycled concrete," Journal of Materials Research and Technology, vol. 9, no. 6, Article ID 13375, 2020.

[4] C. S. Poon and D. Chan, "Paving blocks made with recycled concrete aggregate and crushed clay brick," Construction and Building Materials, vol. 20, no. 8, pp. 569-577, 2006.

[5] C. S. Poon and D. Chan, "Feasible use of recycled concrete aggregates and crushed clay brick as unbound road sub-base," Construction and Building Materials, vol. 20, no. 8, pp. 578585, 2006.

[6] A. M. Azam and D. A. Cameron, "Geotechnical properties of blends of recycled clay masonry and recycled concrete aggregates in unbound pavement construction," Journal of Materials in Civil Engineering, vol. 25, no. 6, pp. 788-798, 2013.

[7] A. Alnedawi and M. A. Rahman, "Recycled concrete aggregate as alternative pavement materials: experimental and parametric study," Journal of Transportation Engineering, Part B: Pavements, vol. 147, no. 1, p. 11, Article ID 4020076, 2021.

[8] C. S. Vieira and P. M. Pereira, "Use of recycled construction and demolition materials in geotechnical applications: a review," Resources, Conservation and Recycling, vol. 103, pp. 192-204, 2015.

[9] J. Wang, M. Ying, F. Liu, and G. Yuan, "Experimental investigation on the stress-dilatancy response of aggregategeogrid interface using parameterized shapes," Construction and Building Materials, vol. 289, Article ID 123170, 2021.

[10] M. Ying, F. Liu, J. Wang, and C. Wang, "Coupling effects of particle shape and cyclic shear history on shear properties of coarse-grained soil-geogrid interface," Transportation Geotechnics, vol. 27, Article ID 100504, 2021.

[11] F. Y. Liu, M. J. Ying, G. H. Yuan, J. Wang, and Z. Y. Gao, "Particle shape effects on the cyclic shear behaviour of the soilgeogrid interface," Geotextiles and Geomembranes, vol. 49, no. 4, pp. 991-1003, 2021.

[12] Z. Wang and W. Richwien, "A study of soil-reinforcement interface friction," Journal of Geotechnical and Geoenvironmental Engineering, vol. 128, no. 1, pp. 92-94, 2002.

[13] F. M. Makkar, S. Chandrakaran, and N. Sankar, "Experimental investigation of response of different granular soil-3D geogrid interfaces using large-scale direct shear tests," Journal of Materials in Civil Engineering, vol. 31, no. 4, Article ID 00419012, 2019.

[14] D. Kim and S. Ha, "Effects of particle size on the shear behavior of coarse grained soils reinforced with geogrid," Materials, vol. 7, no. 2, pp. 963-979, 2014.

[15] Z. Wang, F. Jacobs, and M. Ziegler, "Visualization of load transfer behaviour between geogrid and sand using PFC2D," Geotextiles and Geomembranes, vol. 42, no. 2, pp. 83-90, 2014.

[16] K. Sweta and S. K. K. Hussaini, "Behavior evaluation of geogrid-reinforced ballast-subballast interface under shear condition," Geotextiles and Geomembranes, vol. 47, no. 1, pp. 23-31, 2019.

[17] M. A. Rahman, A. Arulrajah, and J. Piratheenpan, "Resilient modulus and permanent deformation responses of geogridreinforced construction and demolition materials," Journal of Materials in Civil Engineering, vol. 26, no. 3, pp. 1-8, 2014.

[18] J. Wang, F. Y. Liu, and Q. T. Zheng, "Effect of aperture ratio on the cyclic shear behaviour of aggregate-geogrid interfaces," Geosynthetics International, vol. 28, no. 2, pp. 158-173, 2021.
[19] M. Touahaia, V. Sivakumar, and D. Mckelvey, "Shear strength of reinforced-recycled material," Construction and Building Materials, vol. 16, no. 6, pp. 331-339, 2002.

[20] A. Arulrajah, M. A. Rahman, J. Piratheepan, M. W. Bo, and M. A. Imteaz, "Evaluation of interface shear strength properties of geogrid-reinforced construction and demolition materials using a modified large-scale direct shear testing apparatus," Journal of Materials in Civil Engineering, vol. 26, no. 5, pp. 974-982, 2014.

[21] JTJF10-2006, "Technical specification for highway subgrade construction," in Industry Standards of The People's Republic of ChinaChina Communications Press, Beijing, China, 2006.

[22] GB/T50123-1999, "Standard for soil test method," in The Ministry of Water Resources of the People's Republic of ChinaChina Planning Press, Beijing, China, 1999.

[23] B. Liu, H. B. Li, and X. M. Zhu, "Experiment simulation study of strength degradation of rock joints under cyclic shearloading," Chinese Journal of Rock Mechanics and Engineering, vol. 30, no. 10, pp. 2033-2039, 2011.

[24] J. Wang, M. J. Ying, F. Y. Liu, H. T. Fu, J. F. Ni, and J. Shi, "Effect of particle-size gradation on coarse sand-geotextile interface response in cyclic and postcyclic direct shear test," Advances in Civil Engineering, vol. 2020, Article ID 1323296, 11 pages, 2020.

[25] C. N. Liu, Y. H. Ho, and J. W. Huang, "Large scale direct shear tests of soil/PET-yarn geogrid interfaces," Geotextiles and Geomembranes, vol. 27, no. 1, pp. 19-30, 2009.

[26] K. Sweta and S. K. K. Hussaini, "Effect of shearing rate on the behavior of geogrid-reinforced railroad ballast under direct shear conditions," Geotextiles and Geomembranes, vol. 46, no. 3, pp. 251-256, 2018.

[27] F. Y. Liu, X. Lin, and J. Wang, "Influence of particle-size gradation on shear behavior of geosynthetics and sand interfaces," Chinese Journal of Geotechnical Engineering, vol. 32, no. 12, pp. 2575-2582, 2013. 